DNA in the sera of $\mathrm{HBsAg}$ carriers: a marker of active hepatitis B virus replication in the liver. Hepatology $1981 ; 1: 386-91$.

The detection of $\mathrm{HBV}$ DNA in sow DNA in serum by molecular hybridisation: a more sensitive method

24 dettoction of complete $\mathrm{HBV}$ particles. F Med Virol 1982;9:273-80.

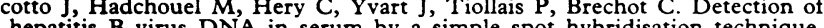
hepatitis B virus DNA in serum by a simple spot hybridisation technique. Comparison with results for other viral markers. Hepatology 1983;3:279-84. Lieberman HM, La Brecque DR, Kew MC, Hadziyannis SJ, Shafritz DA.

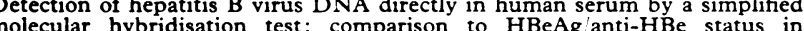
molecular hybridisation test: comparison

26 Monjardino J, Fowler MJF, Montano L, et al. Analysis of hepatitis virus DNA in the liver and serum of $\mathrm{HBe}$ antigen positive chimpanzee carriers. $\mathcal{F}$ Med Virol 1982;9:189-99.
27 Karayiannis P, Fowler MJF, Lok ASF, Greenfield C, Monjardino J, Thomas HC. Detection of serum HBV-DNA by molecular hybridisation: correlation with $\mathrm{HBeAg}$ /anti-HBe status, racial origin, liver histology and hepatocellular

28 Weinstock R, Sweet R, Weiss M, Cedar R, Axel R. Intragenic DNA spacers interrupt the oralbumin gene. Proc Natl Acad Sci USA 1978;75:1295-303.

29 Bancroft WH, Snitbhan R, Scott RM, et al. Transmission of hepatitis $B$ virus to gibbons by exposure to human saliva containing hepatitis $\mathrm{B}$ surface antigen. I Infect Dis 1977;135:79-85.

30 Alter HJ, Purcell RH, Gerin JL, et al. Transmission of hepatitis B to chimpanzees by hepatitis $B$ surface antigen-positive saliva and semen. Infect Immun 1977;16:928-33.

\title{
Chronic ulceration of the leg: extent of the problem and provision of care
}

\author{
M J CALLAM, C V RUCKLEY, D R HARPER, J J DALE
}

\begin{abstract}
A postal survey in two health board areas in Scotland, encompassing a population of about one million, identified 1477 patients with chronic ulcers of the leg. Women outnumbered men by a ratio of $2 \cdot 8: 1$. The median age of the women was 74 and of the men 67 . Seventy two (5\%) were hospital inpatients, $174(12 \%)$ were managed jointly by the primary care team and outpatient departments, and $1201(83 \%)$ were managed entirely in the community.

Efforts to improve the management of chronic ulcers of the leg should focus on primary health care.
\end{abstract}

\section{Introduction}

Chronic ulceration of the leg appears to have perplexed physicians since medical records began. Although there are many reports on its management, little information is available on the overall size and extent of the problem or its clinical course.

Two European surveys into venous disease have been made, providing data on the prevalence of leg ulceration. The first was a study, based on a questionnaire, of the adult population of Klatov in Bohemia in 1961 by Bobek et al. ${ }^{1}$ Those people who indicated that they had evidence of venous disease were subsequently examined. This survey showed that the prevalence of leg ulceration, either open or healed, was $1 \%$. The second and more recent study, of factory workers in Basle, Switzerland, showed a similar proportion. ${ }^{2}$

Information concerning the United Kingdom is almost nonexistent. In 1929 Dickson-Wright suggested a prevalence of $0.5 \%$ but admitted that this figure was an estimate. ${ }^{3}$ In 1951 Boyd et al arrived at a similar figure based on the returns of patients registered as off work due to leg ulceration, ${ }^{4}$ but this figure was probably an underestimate. In a study supplementary to that

\section{Leith Hospital, Edinburgh}

M J CALLAM, MB, FRCSED, senior surgical registrar

Vascular Surgical Unit, Royal Infirmary, Edinburgh

C V RUCKLEY, MB, FRCSED, consultant surgeon

Surgical Unit, Royal Infirmary, Falkirk

D R HARPER, MD, FRCSED, consultant surgeon

Department of Nursing, Lothian Health Board, Edinburgh J J DALE, SRN, MSC, senior nursing officer

Correspondence to: Mrs J J Dale, Lothian and Forth Valley Leg Ulcer Study, 40 Colinton Road, Edinburgh. reported here and based on patients in a group practice in Edinburgh we recently estimated that $1 \%$ of adults suffer from chronic leg ulcers. ${ }^{5}$

Much of the information in reports on leg ulcers is based on small, selected populations, usually patients attending outpatient departments. An understandable conclusion that might be drawn from such reports is that all leg ulcers are managed by dermatologists, surgeons, or physiotherapists. A preliminary survey by our own group, however, showed that most patients were cared for in the community by district nurses and represented a formidable problem for the primary care services not only in terms of numbers but also in various aspects of management. We concluded that the first step towards improving care was to obtain better information on the scale of the problem, the clinical course of the condition, and how care was being provided.

The Lothian and Forth Valley leg ulcer study was therefore set up in 1981. This paper reports the first phase, the main aims of which were to establish a point prevalence of leg ulcers and to find out who was providing the care.

\section{Methods}

The survey was carried out in 1981-2 in the neighbouring health board areas of Lothian and Forth Valley, which have a mixed urban and rural population of about one million. The objective was to identify all patients receiving treatment for chronic leg ulceration from any branch of the National Health Service at the time of the survey.

To identify all patients receiving treatment in the community recording forms were sent to all general practitioners, district and occupational nurses, and wardens of old people's homes. To identify patients receiving either outpatient or inpatient care at a hospital forms were sent to outpatient departments, physiotherapy departments, and inpatient wards of general hospitals and all acute and long stay hospitals. In each case the correspondent was asked to identify all the patients currently undergoing treatment for active chronic leg ulceration or who had received treatment within three months. Efforts were made to obtain replies from non-responders by means of follow up letters and telephone calls.

The resulting returns were cross checked to ensure that patients reported from more than one source were included only once in the final total.

\section{Results}

Of the 572 general practitioners approached, only 37 refused to cooperate with the study. Complete returns were obtained from all other correspondent groups. Notifications of 2128 patients were received, of which 651 were reported from more than one source, giving a total of 1477 patients $(1765(83 \%)$ were reported by general practitioners, district nurses, occupational health services, and old people's homes; and $104(5 \%)$ by physiotherapy departments, $148(7 \%)$ by 
outpatient departments, and $111\left(5^{\circ}{ }_{0}\right)$ by hospital inpatient departments). When patients were reported from more than one source preference was given to those reported by general practitioners and district nurses as the primary providers of care. By these criteria 1282 $\left(87^{\circ} \circ\right)$ were reported from the community and $195(13 \%)$ from the hospitals.

From these figures the point prevalence of active leg ulceration known to health care workers in this area was established as $1.48 / 1000$ total population. A considerable variation between geographical areas was evident, the range being $1 \cdot 35-2 \cdot 09 / 1000$ population.

The patients were mostly women. Out of the total of 1477 patients who were identified by the survey, only 388 were men and 1089 women (ratio $1: 2 \cdot 8$ ). The table shows the distribution by age and sex of the 1311 patients on whom information on age was available. The median age of the men was 67 (range 22-96) and of the women 74 (range 26-100).

Distributions of age and sex of patients $(n=1311)$ with chronic leg ulcers

\begin{tabular}{lccccc}
\hline & \multicolumn{2}{c}{ Men } & & \multicolumn{2}{c}{ Women } \\
\cline { 2 - 3 } \cline { 6 - 6 } Age* (years) & No $(\%)$ & Prevalencet & & No $(\%)$ & Prevalence ${ }^{\circ}$ \\
\hline$<25$ & $1(<1)$ & $1: 191846$ & & \\
$25-34$ & $9(2)$ & $1: 7306$ & & $3(<1)$ & $1: 24596$ \\
$35-44$ & $17(5)$ & $1: 2976$ & & $14(2)$ & $1: 3678$ \\
$45-54$ & $52(15)$ & $1: 922$ & & $57(6)$ & $1: 897$ \\
$55-64$ & $77(22)$ & $1: 576$ & & $153(16)$ & $1: 327$ \\
$65-74$ & $112(32)$ & $1: 290$ & & $288(30)$ & $1: 158$ \\
$75-84$ & $66(19)$ & $1: 195$ & & $315(33)$ & $1: 86$ \\
$>85$ & $13(<4)$ & $1: 139$ & & $134(13)$ & $1: 53$ \\
\hline Total & 347 & & 964 &
\end{tabular}

* In 166 patients information on age was not available.

+Prevalences specific to age and sex were calculated using Registrar General's census statistics for 1981 for area covered by the survey and corrected for 166 patients whose statistics for 1981 for area
ages were not available.

\section{Discussion}

In seeking to quantify the great demand that the care of leg ulcers places on the health service we have highlighted the difficulties experienced in obtaining accurate and comprehensive information.

The first obstacle was that care is provided for this disease by many different specialties and in almost every part of the health service. Patients seen periodically in outpatient departments were often cared for by the district nurse between appointments. Patients also moved from one source of care to another during the survey. For this reason, although the totals attributed to each source of care are too high, the proportional distribution between primary and hospital care of roughly $5: 1$ is a fair reflection of what is happening in practice. Only $6 \%$ of general practitioners refused to collaborate, but we were nevertheless able to make up much of this deficit from information provided by other respondents in nospitals and the community, from whom total collaboration was obtained.

The clinical course of chronic leg ulceration is one of episodes of recurrence followed by periods when the ulcer is healed. Our survey, which looked at the point prevalence, identified only those patients who had had active ulceration within three months before the time of the survey and could not identify most patients who were "between ulcers." We chose to refer to point rather than period prevalence because, although we asked respondents to report ulcers that had occurred within the previous three months, virtually all ulcers were either open or had healed within one or two weeks of the inquiry. Thus the prevalence of active leg ulceration of $1 \cdot 5 / 1000$ population that we established represents only a proportion of the population of patients with chronic leg ulcers. The figures for the overall prevalence of the condition from our supplementary survey ${ }^{5}$ and the work of Bobek et $a l^{1}$ and Widmer ${ }^{2}$ suggest that at any one time only $20-25 \%$ of ulcers are open. As one ulcer opens, however, another heals, and so the figure of $1.5 / 1000$ represents the actual workload at any one time in terms of active ulceration.

A further obstacle to obtaining a complete survey is that we do not know what proportion of patients fail to report their ulcers to their doctors. In some instances that is because they think that they are able to dress the lesion themselves. Others may conceal the ulcer for various reasons such as fear of amputation. The size of this group is unknown, but we believe it to be small. It is in one sense irrelevant as we were concerned here with the scale of the problem as it impinged on health care resources.

Almost three times as many women as men were identified in the study. The table shows the distributions of age and sex among the 1311 patients whose ages were known, together with prev!ences calculated from the Registrar General's census statistics for 1981 for the same geographical area. Our findings contrast noticeably with the figures found in the Basle study, in which the ratio was $1: 1 .^{2}$ That study, however, was only of workers in factories, most of whom were men. All were of working age. Thus elderly women with leg ulcers would not have been detected. The survey by Bobek et $a l^{1}$ comprised the entire adult population and showed a preponderance of women with a ratio of $1: 1.5$ (men:women). Anning, who reviewed a large series of referrals to hospitals in the 1950 s, also showed a preponderance of women with a ratio of $1: 2 \cdot 5 .^{6} \mathrm{It}$ appears, therefore, that this condition is more common in women.

In considering the distribution of age and sex among our patients it is important to note that the ages given are those at the time of the survey and not at onset of the first episode of ulceration. In most cases the condition had been present for many years. In effect, this caused an accumulation of patients in the older age groups, particularly the women, who have a greater life expectancy. Two points can be noted from the table. Firstly, even though the age at the time of survey instead of the age at onset of ulceration was used, just under half of the men and a quarter of the women were below the age of retirement. Thus leg ulceration is not only a problem for the elderly but also affects younger people, often resulting in substantial loss of working time. Secondly, as people's life span increases the size of the problem of leg ulcers will probably increase.

Identification of the sources of these patients was based on current or recent treatment and therefore broadly equates with the current provision of all or part of the care. Clearly, most patients with ulcers ( $87 \%$ ) are managed by the primary care team, while a fairly small proportion are wholly under hospital care $(13 \%)$.

If the figures from this study were extrapolated to the whole of the United Kingdom they would suggest that there are roughly 100000 patients with active leg ulceration at any one time, drawn from a population with leg ulcers of 400000 . Much the largest share of the workload falls on district nurses. Any attempt to improve overall results must therefore include improvement of care in the community. Improvement in hospital care alone would make little impact.

Having ascertained the scale of the problem and learnt where care is being provided and by whom, our next objective was to study the clinical course of leg ulceration. We have assessed 600 of these patients in greater detail and shall report the findings later.

We thank our medical, nursing, and physiotherapy colleagues for their help. This study was made possible by a grant from the Health Service Research Committee of the Scottish Home and Health Department.

\section{References}

1 Bobek K, Cajzl L, Cepelák V, Slaisova V, Opatzny K, Barcal R. Etude de la frequence des maladies phlebologiques et de l'influence de quelques facteurs

Widmer LK. Peripheral venous disorders: prevalence and sociomedical importance.

3 Dickson-Wright A. The treatment of indolent ulcer of the leg. Lancet 1931 ; : 457-60.

4 Boyd AM, Jepson RP, Ratcliffe AH, Rose SS. The logical management of chronic ulcers of the leg. Angiology 1952;3:207-15.

5 Dale JJ, Callam MJ, Ruckley CV, Harper DR, Berrey PN. Chronic ulcers of the leg: a study of prevalence in a Scottish community. Health Bull (Edinb) $1983 ; 41: 310-4$

Anning ST. Leg ulcers: their causes and treatment. London: J \& A Churchill Ltd, Accepted 20 March 1985) 